\title{
Were We Able to Reduce Cardiac Doses in Breast Cancer Radiotherapy Over Time?
}

\author{
(1) Pelin Altınok ${ }^{1}$, (1) Latif Korkmaz², (10) Ayse Altınok ${ }^{2}$, (1) Nuran Beşe \\ ${ }^{1}$ Department of Radiation Oncology, University of Health Sciences Turkey, Ümraniye Training and Research Hospital, İstanbul, Turkey \\ ${ }^{2}$ Research Institute of Senology, Acıbadem Maslak Hospital, İstanbul, Turkey
}

\begin{abstract}
Objective: In this study, we aimed to review the heart and left coronary artery doses over the years in patients who received breast cancer radiotherapy (RT).

Materials and Methods: A total of 436 breast cancer patients of 2 RT centers treated between the years 2010 and 2018 were included. The mean heart doses (HeartDmean-HDM) and left coronary artery mean doses (LDM) were analyzed using nonparametric tests. The conventional RT (CRT) was $50 \mathrm{~Gy} / 2$ Gy in 5 weeks, and the hypofractionated RT (HRT) was 40.05 Gy/2.67 Gy in 3 weeks. Boost was applied as 10-16 Gy/2 Gy for CRT and 10 Gy/2.5 Gy for HRT. An equivalent conventional total dose of 2 Gy/fraction (EQD2) was taken into account for HRT.

Results: HDM was $107 \pm 104$ cGy, and LDM was $288 \pm 209$ cGy for the entire group. HDM was significantly lower in patients with breast-conserving surgery $(99 \pm 94 \mathrm{cGy})$ than that in those with mastectomy $(128 \pm 124 \mathrm{cGy})(\mathrm{p}<0.001)$. Field-in-field intensity-modulated RT technique significantly reduced the doses compared to volumetric applications $(104 \pm 95 \mathrm{cGy}$ vs $141 \pm 38 \mathrm{cGy} ; \mathrm{p}=0.002)$. HDM was significantly increased with lymphatic RT $(132 \pm 58 \mathrm{cGy}$ vs $112 \pm 115 \mathrm{cGy} ; \mathrm{p}<0.001)$. The addition of internal mammary volumes significantly increased HDM ( $<0.001)$. No significant effect of boost was observed $(\mathrm{p}=0.96)$. For both CRT and HRT regimens, HDM values were significantly lower after the year 2014 (right side $\mathrm{p}<0.001$, left side $\mathrm{p}=0.01$ ). In the left side CRT, HDM was 1.74 Gy before 2014 and $1.3 \mathrm{~Gy}$ after 2014 and 1.0 and $1.19 \mathrm{~Gy}$, respectively, for the right side.
\end{abstract}

Conclusion: All efforts to reduce the cardiac doses will likely reduce long-term side effects.

Keywords: Breast cancer, radiotherapy, cardiac toxicity

Cite this article as: Alınok P, Korkmaz L, Alınok A, Beşe N. Were We Able to Reduce Cardiac Doses in Breast Cancer Radiotherapy Over Time? Eur J Breast Health 2021; 17(2): 145-149

\section{Key Points}

- Cardiac toxicity is the most important cause of morbidity and mortality of breast cancer radiotherapy. The mean heart dose is the major predictor of this late side effect.

- The significant increase of the mean heart doses is observed after mastectomy, with the application of volumetric techniques and adding lymphatic irradiation to the treatment. The results were the same for both conventional and hypofractionated regimens.

- The significant reduction of mean heart doses could be achieved after 2014.

\section{Introduction}

Cardiac toxicity due to radiotherapy (RT) in breast cancer has been an issue which has been emphasized for many years. The risk begins within a few years after treatment and may continue to 15-20 years. Cardiac risk factors and some of the systemic treatments that patient receive contribute to this toxicity. Owing to the development of computed tomography and its integration into RT plans after the 1990s, the exact cardiac doses and their long-term effects could be more accurately observed (1). Over the years, cardiac and left main coronary artery doses due to breast RT were reviewed, and treatment practices were developed to reduce these doses. Studies published in the recent years showed that after 2014-2015, a significant decrease has been achieved. In this study, we aimed to review the heart and left coronary artery doses over the years in patients who received breast cancer RT. 


\section{Materials and Methods}

After the approval of ethical review board, Acibadem University (decision no: 2020-03/04, date: 27.02.2020) 436 breast cancer patients of two different RT centers in Turkey treated between the years 2010 and 2018 were included. The impacts of variables as treatment side (left or right), fractionation, treatment volumes, energy used, presence of respiratory control, presence of boost, type of surgery [mastectomy or breast-conserving surgery (BCS)], and the treatment date on the mean heart doses (HeartDmean-HDM) and left coronary artery mean doses (LDM) were retrospectively analyzed. EQD2 was taken into account by accepting heart alpha/beta ratio as 3 for hypofractionated regimens.

The distribution of left and right breast cancers were almost equal ( $49 \%$ vs $51 \%$ ). The majority of the patients had BCS (72.5\%). The irradiation technique, to a great extent, was field-in-field intensitymodulated RT (FIF-IMRT) (97.2\%). Respiratory control was performed in 169 patients (38.8\%). More than half of the patients received breast RT only (51.8\%). Mammaria interna irradiation was performed in 138 patients (31.7\%). The percentage of patients with a boost was $56 \%$ (Table 1$)$.

\section{Statistical analysis}

The impact of variables was analyzed using nonparametric tests (IBM SPSS Statistics V20).

\section{Results}

When all patients were evaluated together, the average HDM was determined to be 107 cGy [standard deviation, (SD): 104 (1-1290)], and LDM was 288 cGy [SD: 209 (0-1124)]. HDM was significantly lower in patients with BCS $(99 \pm 94 \mathrm{cGy})$ than that in those with mastectomy $(128 \pm 124$ cGy $) \quad(\mathrm{p}<0.001)$. FIF-IMRT technique significantly reduced the doses compared to the volumetric applications (dynamic IMRT and volumetric arc therapy) (104 \pm 95 cGy vs $141 \pm 38$ cGy; $\mathrm{p}=0.002$ ). HDM was significantly higher in patients who received lymphatic volume irradiation in addition to whole breast/ chest wall $(128 \pm 58$ cGy vs $90 \pm 115 ; \mathrm{p}<0.001)$. The addition of internal mammary volumes to supra and axillary lymphatics significantly increased HDM in patients receiving lymphatic RT $(\mathrm{p}<0.001)$. No significant effect of boost was observed $(\mathrm{p}=0.96)$.

When HDM values were evaluated together for all years, the "time" factor was accepted as the years before and after 2014 since nonparametric tests indicated a significant change in this year. The treatment plans were also evaluated separately according to conventional and hypofractionated RT and also according to treatment side (left vs right breast).

A total of 163 patients received RT to right breast with conventional fractionation. BCS was applied to 98 (60.1\%). The FIF-IMRT rate was $97.5 \%$. A total of 80 patients received whole breast/chest wall irradiation (WBI/CW) (49.1\%), 46 patients (28.2\%) received WBI/ $\mathrm{CW}$ and were irradiated at any lymphatic volume(s), and 37 patients (22.7\%) were irradiated at all lymphatic volumes along with WBI/ CW. A total of $53(32.5 \%)$ patients were treated before 2014 and $110(67.5 \%)$ in 2014 and after [HDM mean, median and SD values were 101 cGy, $95 \pm 39$ cGy, and 71 cGy, 57 \pm 119 cGy, respectively, for before and after $2014(\mathrm{p}<0.001)$ ]. The addition of internal mammary volumes significantly increased HDM for patients with conventionally treated right breast cancer $(\mathrm{p}=0.047)$. There was no difference in terms of type of surgery, respiratory control, and addition of boost.

There were 61 patients who received right breast irradiation with hypofractionation. No analysis was made for surgery, respiratory control, lymphatic RT, and boost due to the inequality of distribution between the comparison groups. HDM mean, median doses, and SD values were significantly different for patients treated before 2014 and

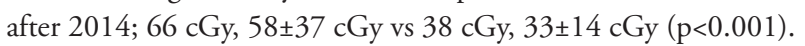

Table 1. Treatment characteristics of the patients

\begin{tabular}{|c|c|c|c|c|}
\hline & $\begin{array}{l}\text { Left-sided CRT } \\
\qquad(n=177)\end{array}$ & $\begin{array}{l}\text { Right-sided CRT } \\
\qquad(n=163)\end{array}$ & $\begin{array}{l}\text { Left-sided HRT } \\
\qquad(\mathrm{n}=35)\end{array}$ & $\begin{array}{l}\text { Right-sided HRT } \\
(n=61)\end{array}$ \\
\hline \multirow{2}{*}{ Operation } & BCS = $126(71 \%)$ & $\mathrm{BCS}=98(60 \%)$ & BCS $=34(97 \%)$ & $\mathrm{BCS}=58(95 \%)$ \\
\hline & $M=51(29 \%)$ & $M=65(40 \%)$ & $M=1(3 \%)$ & $M=3(5 \%)$ \\
\hline \multirow{2}{*}{ RT technique } & FIF-IMRT = 169 (95\%) & FIF-IMRT = 160 (98\%) & FIF-IMRT = 35 (100\%) & FIF-IMRT = 61 (100\%) \\
\hline & Volumetric R = 8 (5\%) & Volumetric RT = $3(2 \%)$ & Volumetric RT $=0$ & Volumetric RT = 0 \\
\hline \multirow{2}{*}{ Breath hold } & Present = 107 (60\%) & Present = 29 (18\%) & Present = 30 (86\%) & Present = $3(5 \%)$ \\
\hline & Absent $=70(40 \%)$ & Absent = $134(82 \%)$ & Absent = $5(14 \%)$ & Absent = $58(95 \%)$ \\
\hline \multirow{2}{*}{$\begin{array}{l}\text { Lymphatic } \\
\text { volume } \\
\text { irradiation }\end{array}$} & Present = 102 (58\%) & Present = 83 (51\%) & Present = 2 (6\%) & Present = 6 (10\%) \\
\hline & Absent $=75(42 \%)$ & Absent = $80(49 \%)$ & Absent = 33 (94\%) & Absent = 55 (90\%) \\
\hline \multirow{2}{*}{ MI irradiation } & Present = 71 (40\%) & Present = 67 (41\%) & Present = $1(3 \%)$ & Present = 2 (3\%) \\
\hline & Absent $=106(60 \%)$ & Absent = $96(59 \%)$ & Absent = $34(97 \%)$ & Absent = $59(97 \%)$ \\
\hline \multirow{2}{*}{ Boost } & Boost = $116(65 \%)$ & Boost $=82(50 \%)$ & Boost $=18(51 \%)$ & Boost $=28(46 \%)$ \\
\hline & No boost $=61(35 \%)$ & No boost $=81(50 \%)$ & No boost = 17 (49\%) & No boost $=33(54 \%)$ \\
\hline \multirow{2}{*}{ Time Interval } & $<2014=62(35 \%)$ & $<2014=53(32 \%)$ & $<2014=5(14 \%)$ & $<2014=11(18 \%)$ \\
\hline & $\geq 2014=115(65 \%)$ & $\geq 2014=110(68 \%)$ & $\geq 2014=30(86 \%)$ & $\geq 2014=50(82 \%)$ \\
\hline
\end{tabular}


A total of 177 left-sided patients received RT with conventional fractionation. Most of them were BCS (71.2\%). FIF-IMRT was applied in $95 \%$ of patients. Respiratory control was applied in 107 patients (60.5\%). Lymphatic RT was absent in 75 patients (42.4\%). A total of 62 patients were treated before 2014. HDM mean, median, and SD

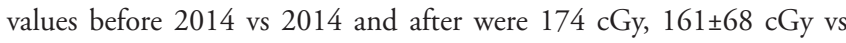
$130 \mathrm{cGy}$, and $127 \pm 48 \mathrm{cGy}$, respectively $(\mathrm{p}<0.001)$. HDM values were significantly lower for patients with BCS ( $p=0.001)$, without any lymphatic volume irradiation $(\mathrm{p}<0.001)$, or no mammaria interna RT $(\mathrm{p}<0.001)$. Similarly, LDM was significantly lower if there was BCS $(\mathrm{p}=$ $0.001)$, there was no lymphatic RT ( $\mathrm{p}<0.001)$, and there was no internal mammary RT $(\mathrm{p}<0.001)$. LDM mean, median, and SD values were also significantly higher for patients treated before 2014 (390 cGy, 337 \pm 180 cGy vs 429 cGy, $406 \pm 154$ cGy, respectively) ( $p=0.012$ ). Statistical significance was not determined in other parameters evaluated.

Surgery, nodal RT, MI RT, and RT technique could not be evaluated in 35 patients who had left HRT because of distribution inequality. Five patients were irradiated before 2014, and the remaining 30 were irradiated in or after 2014. The HDM mean for patients treated before 2014 was $302 \mathrm{cGy}$, and for patients treated in or after 2014, the HDM mean was 115 cGy $(\mathrm{p}=0.01)$ (Table 2 and Table 3$)$.

Table 2. Mean heart doses (median cGy \pm standard deviation)

\begin{tabular}{|c|c|c|c|c|}
\hline & $\begin{array}{l}\text { Left-sided CRT } \\
\qquad(n=177)\end{array}$ & $\begin{array}{l}\text { Right-sided CRT } \\
\quad(n=163)\end{array}$ & $\begin{array}{l}\text { Left-sided HRT } \\
\qquad(n=35)\end{array}$ & $\begin{array}{l}\text { Right-sided HRT } \\
\qquad(n=61)\end{array}$ \\
\hline \multirow{2}{*}{ Operation } & $\mathrm{BCS}=127 \pm 58$ & $\mathrm{BCS}=61 \pm 30$ & $\mathrm{BCS}=84 \pm 229$ & $\mathrm{BCS}=37 \pm 17$ \\
\hline & $M=159 \pm 57$ & $M=76 \pm 154$ & $M=$ null & $M=35 \pm 76$ \\
\hline \multirow{2}{*}{ RT technique } & FIF-IMRT = $138 \pm 60$ & FIF-IMRT $=67 \pm 34$ & FIF-IMRT $=84 \pm 226$ & FIF-IMRT $=37 \pm 22$ \\
\hline & Volumetric RT = 149 \pm 31 & Volumetric RT $=147 \pm 68$ & Volumetric RT = null & Volumetric RT = null \\
\hline \multirow{2}{*}{ Breath hold } & Present $=134 \pm 49$ & Present $=67 \pm 42$ & Present $=83 \pm 173$ & Present $=32 \pm 33$ \\
\hline & Absent $=149 \pm 71$ & Absent $=70 \pm 110$ & Absent $=122 \pm 424$ & Absent $=37 \pm 22$ \\
\hline \multirow{2}{*}{ Lymphatic volume irradiation } & Present $=156 \pm 60$ & Present $=68 \pm 38$ & Present $=106 \pm 21$ & Present $=54 \pm 47$ \\
\hline & Absent $=113 \pm 53$ & Absent $=70 \pm 139$ & Absent $=84 \pm 233$ & Absent $=35 \pm 17$ \\
\hline \multirow[t]{2}{*}{ MI irradiation } & Present $=158 \pm 56$ & Present $=72 \pm 38$ & Present = null & Present $=108 \pm 74$ \\
\hline & Absent $=124 \pm 58$ & Absent $=63 \pm 128$ & Absent $=84 \pm 229$ & Absent $=35 \pm 17$ \\
\hline \multirow{2}{*}{ Boost } & Boost $=128 \pm 60$ & Boost $=64 \pm 138$ & Boost $=84 \pm 223$ & Boost $=32 \pm 10$ \\
\hline & No boost $=153 \pm 57$ & No boost $=73 \pm 36$ & No boost $=84 \pm 236$ & No boost $=47 \pm 27$ \\
\hline \multirow{2}{*}{ Time interval } & $<2014=161 \pm 68$ & $<2014=95 \pm 39$ & $<2014=123 \pm 424$ & $<2014=58 \pm 37$ \\
\hline & $\geq 2014=127 \pm 48$ & $\geq 2014=57 \pm 119$ & $\geq 2014=83 \pm 173$ & $\geq 2014=33 \pm 14$ \\
\hline
\end{tabular}

RT: Radiotherapy; CRT: Conventional RT; HRT: Hypofractionated RT; BCS: Breast-conserving surgery; M: Mastectomy; FIF-IMRT: Field-in-field intensitymodulated radiotherapy; MI: Mammaria interna; n: Number

Table 3. Mean heart doses changing along the years according to treatment side and schedule

\begin{tabular}{|c|c|c|c|}
\hline & $\begin{array}{c}\text { Before } 2014 \\
\text { Heart Dmean } \\
\text { Mean, median; SD } \\
\text { (min-max) cGy }\end{array}$ & $\begin{array}{l}2014 \text { and after } \\
\text { Heart Dmean } \\
\text { Mean, median; SD } \\
\text { (min-max) cGy }\end{array}$ & p-value \\
\hline $\begin{array}{l}\text { Right side } \\
\text { conventional }\end{array}$ & $\begin{array}{c}n=53 \\
101 ; 95 \pm 39 \\
(1-268)\end{array}$ & $\begin{array}{c}n=110 \\
71 ; 57 \pm 119 \\
(9-1290)\end{array}$ & $<0.0001$ \\
\hline $\begin{array}{l}\text { Right side } \\
\text { hypofractionated }\end{array}$ & $\begin{array}{c}n=10 \\
66 ; 58 \pm 37 \\
(32-161)\end{array}$ & $\begin{array}{c}n=51 \\
38 ; 33 \pm 14 \\
(12-89)\end{array}$ & 0.001 \\
\hline $\begin{array}{l}\text { Left side } \\
\text { conventional }\end{array}$ & $\begin{array}{c}n=62 \\
161 ; 174 \pm 68 \\
(74-388)\end{array}$ & $\begin{array}{c}n=115 \\
127 ; 130 \pm 48 \\
(1-357)\end{array}$ & $p<0.0001$ \\
\hline $\begin{array}{l}\text { Left side } \\
\text { hypofractionated }\end{array}$ & $\begin{array}{c}n=5 \\
302 ; 123 \pm 424 \\
(84-1060)\end{array}$ & $\begin{array}{c}n=30 \\
115 ; 83 \pm 173 \\
(55-1030)\end{array}$ & 0.01 \\
\hline
\end{tabular}




\section{Discussion and Conclusion}

The contribution of RT to breast cancer-related survival is well-known $(2,3)$. In prolonged survival, late side effects of RT may increase the patients' morbidity and mortality. It may cause an increase in cardiac mortality by creating ischemic heart disease especially in left breast irradiation (4). Considering that the cardiac side effects occur in a period of up to 15-20 years after RT, it should be remembered that the RT technique applied in studies examining this toxicity belongs to about 10 years before.

In the old meta-analysis conducted by Cuzick et al. (5) which included studies comparing surgery and surgery + adjuvant RT, it was revealed that cardiac deaths were higher with RT in 10 years. However, decreased breast cancer deaths with RT contributed to the overall survival rates ( 49.5 fewer breast cancer deaths versus 64.2 cardiac death increase). In a more recent meta-analysis examining studies between 1966 and 2015, data of over 1 million patients were used, the relative risk of coronary artery disease was 1.30 , and the relative risk of cardiac mortality was 1.38 in patients receiving RT (6).

The case-control study conducted by Darby et al. (4) including the years 1958-2001 in patients who received RT in Sweden and Denmark is a landmark study in terms of RT-related ischemic heart disease. This study revealed the dose-response relationship and showed that every $1 \mathrm{~Gy}$ increase in the average heart dose increased the risk of ischemic heart disease by $7.4 \%$ (4). This study also states that the mean heart dose is a better marker for evaluating major coronary complications. HDM was found to be higher in left side irradiation (4), and the risk of cardiac death was consequently greater (6).

It can be observed that HDM reported by different studies varies throughout the years. As an example, in the 2013 study of Darby et al. (4), covering the years 1958-2001, the left side HDM was 6.6 Gy, and the right side was $2.9 \mathrm{~Gy}$, and the doses increased significantly when lymphatic irradiation and especially MI RT were performed. The study, in which Taylor et al. (7) reviewed 149 studies, covering the years 2003-2013, found that the left side HDM was 5.4 Gy and the right-side HDM 3.3 Gy (7).

A better understanding of cardiac toxicity has led to advances in current techniques for lowering heart doses and accelerated the applications of better contouring (8), respiratory-controlled RT (9), and different RT applications (4).

In the article published by the Michigan Radiation Oncology Quality Consortium (MROQC), 4,688 patients, irradiated between 2012 and 2015, were examined. These patients were evaluated for left- versus right-sided RT and conventional versus accelerated RT. In the left-sided irradiation, HDM decreased significantly over the mentioned 4-year period (for conventional RT, 2.19 Gy in 2012, 1.65 Gy in 2015; for accelerated RT, 1.70 Gy in 2012, 1.22 Gy in 2015). In conventional RT patients, excessive breast separation, nodal irradiation, MI irradiation, the use of IMRT, and additional boost increased HDM. Separation, boost, and IMRT use were found to be effective in the increase of HDM in those with accelerated RT (10).

Another more recent review from Canada examined 99 studies conducted between 2014 and 2017 after Taylor et al. (7) (11). The average HDM in this study is $3.4 \mathrm{~Gy}$ and is lower than that of Taylor's study (5.2 Gy). An increase in HDM doses has been shown with
IMRT instead of tangential RT. In addition, a significant decrease was observed in HDM in the left-sided irradiation each year; the average HDM was 4.6 Gy in 2014, and it decreased to 2.6 in 2017.

In Taylor's review, the average HDM of left side between 2003 and 2013 was 5.4 Gy, while in the 2014-2017 Canada review, it was 3.6 Gy. The right-side average HDM is 3.3 Gy in Taylor's compilation and 1.9 Gy in Canada. These doses appear higher than in the Michigan study.

In our study, while the average HDM doses decreased between 2010 and 2018, the threshold was found as 2014. In conventional RT applications on the left side, the mean HDM was 1.74 Gy before 2014 and 1.3 Gy after 2014 and 1.0 and 1.19 Gy, respectively, for the right side. These values are lower than the Taylor and Canada reviews and are more compatible with those of the Michigan study. Lymphatic RT and MI irradiation significantly increased the mean HDM doses as in other studies. Reduced HDM doses were achieved with FIF-IMRT as in the Canada study, but addition of boost dose did not statistically differ HDM unlike MROQC study.

However, since the right-left side, conventional and hypofractionated regimens were evaluated separately, and the number of patients per group led to distribution inequality in some important parameters such as boost application and was not found suitable for statistical evaluation. Significance can be gained with higher number of patients.

At least 5-10 years of long-term follow-up is needed to determine whether there are fewer cardiac events with decreasing heart doses and if local recurrence rates increase in return. We haven't reached that follow-up time yet. So, this could be the topic for subsequent studies.

As the current evidence reveals, all effort should be put into lower cardiac doses as much as possible.

Ethics Committee Approval: This study was approved by the Acıbadem University Ethics Committee (decision no: 2020-03/04, date: 27.02.2020).

Informed Consent: Retrospective study.

Peer-review: Externally peer-reviewed.

\section{Authorship Contributions}

Conception: P.A., A.A., N.B.; Design: P.A., A.A., N.B.; Supervision: P.A., A.A., N.B.; Materials: P.A., L.K., A.A., N.B.; Data Collection and/or Processing: P.A., L.K.; Analysis and/or Interpretation: P.A.; Literature Review: N.B.; Writing: P.A., N.B.; Critical Review: A.A., N.B.

Conflict of Interest: No conflict of interest was declared by the authors.

Financial Disclosure: The authors declared that this study received no financial support.

\section{References}

1. Darby SC, McGale R, Taylor CW, Peto R. Long-term mortality from heart disease and lung cancer after radiotherapy for early breast cancer: Prospective cohort study of 300,000 women in US SEER cancer registries. Lancet Oncol 2005; 6: 557-565. (PMID: 16054566) [CrossRef]

2. Early Breast Cancer Trialists' Collaborative Group; McGale P, Taylor C, Correa C, Cutter D, Duane F, Ewertz M, et al. Effect of radiotherapy after mastectomy and axillary surgery on 10-year recurrence and 20-year breast cancer mortality: Meta-analysis of individual patient data for 8135 
women in 22 randomised trials. Lancet 2014; 383: 2127-2135. (PMID: 24656685) [CrossRef]

3. Darby S, McGale P, Correa C, Taylor C, Arriagada R, Clarke M, et al. Effect of radiotherapy after breast-conserving surgery on 10-year recurrence and 15-year breast cancer death: Meta-analysis of individual patient data for 10,801 women in 17 randomised Trials. Lancet 2011; 378: 1707-1716. (PMID: 22019144) [CrossRef]

4. Darby SC, Ewertz M, McGale P, Bennet AM, Blom-Goldman U, Bronnum D, et al. Risk of ischemic heart disease in women after radiotherapy for breast cancer. N Engl J Med 2013; 368: 987-998. (PMID: 23484825) [CrossRef]

5. Cuzick J, Stewart H, Rutqvist L, Houghton J, Edwards R, Redmond C, et al. Cause-specific mortality in long-term survivors of breast cancer who partici- pated in trials of radiotherapy. J Clin Oncol 1994; 12: 447-453. (PMID: 8120544) [CrossRef]

6. Cheng YJ, Nie XY, Ji CC, Lin XX, Liu LJ, Chen XM, et al. Long-term cardiovascular risk after radiotherapy in women with breast cancer. J Am Heart Assoc 2017; 6: e005633. (PMID: 28529208) [CrossRef]
7. Taylor CW, Wang Z, Macaulay E, Jagsi R, Duane F, Darby SC. Exposure of the heart in breast cancer radiation therapy: A systematic review of heart doses published during 2003 to 2013. Int J Radiat Oncol Biol Phys 2015; 93: 845-853. (PMID: 26530753) [CrossRef]

8. Duane F, Aznar MC, Bartlett F, Cutter DJ, Darby SC, Jagsi R, et al. A cardiac contouring atlas for radiotherapy. Radiother Oncol 2017; 122:416-422. (PMID: 28233564) [CrossRef]

9. Shah C, Badiyan S, Berry S, Khan AJ, Goyal S, Schulte K, et al. Cardiac dose sparing and avoidance techniques in breast cancer radiotherapy. Radiother Oncol 2014; 112: 9-16. (PMID: 24813095) [CrossRef]

10. Pierce LJ, Feng M, Griffith KA, Jagsi R, Boike T, Dryden D, et al. Recent time trends and predictors of heart dose from breast radiation therapy in a large quality consortium of radiation oncology practices. Int J Radiat Oncol Biol Phys 2017; 99: 1154-1161. (PMID: 28927756) [CrossRef]

11. Drost L, Yee C, Lam H, Zhang L, Wronski M, McCann C, et al. A systematic review of heart dose in breast radiotherapy. Clin Breast Cancer 2018; 18: e819-e824. (PMID: 29980429) [CrossRef] 